\title{
An Entomopathogenic Nematode Extends Its Niche by Associating with Different Symbionts
}

\author{
Abigail M. D. Maher ${ }^{1}$ - Mohamed A. M. Asaiyah ${ }^{1,3}$ - Caroline Brophy $^{2}$. \\ Christine T. Griffin ${ }^{1}$
}

Received: 20 April 2016/Accepted: 2 August 2016/Published online: 20 August 2016

(C) Springer Science+Business Media New York 2016

\begin{abstract}
Bacterial symbionts are increasingly recognised as mediators of ecologically important traits of their animal hosts, with acquisition of new traits possible by uptake of novel symbionts. The entomopathogenic nematode Heterorhabditis downesi associates with two bacterial symbionts, Photorhabdus temperata subsp. temperata and P. temperata subsp. cinerea. At one intensively studied coastal dune site, $P$. temperata subsp. cinerea is consistently more frequently isolated than $P$. temperata subsp. temperata in H. downesi recovered from under the bare sand/Ammophila arrenaria of the front dunes (where harsh conditions, including drought, prevail). This is not the case in the more permissive closed dune grassland further from the sea. No differences were detected in ITS1 (internal transcribed spacer) sequence between nematode lines carrying either of the two symbiont subspecies, nor did they differ in their ability to
\end{abstract}

Sequences GenBank accession numbers for Heterorhabditis downesi: KU573057, KU573058, KU573059, KU573060, KU573061,

KU573062

Photorhabdus temperata subspecies temperata: KU559326, KU559327, KU559328

Photorhabdus temperata subspecies cinerea: KU559323, KU559324, KU559325

Electronic supplementary material The online version of this article (doi:10.1007/s00248-016-0829-2) contains supplementary material, which is available to authorized users.

Christine T. Griffin

christine.griffin@nuim.ie

1 Department of Biology, Maynooth University, Maynooth, County Kildare, Ireland

2 Department of Mathematics and Statistics, Maynooth University, Maynooth, County Kildare, Ireland

3 Department of Biology, Azzaytuna University, Tarhouna, Libya utilise insects from three orders. The two symbionts could be readily swapped between lines, and both were carried in equal numbers within infective juveniles. In laboratory experiments, we tested whether the symbionts differentially affected nematode survival in insect cadavers that were allowed to dry. We assessed numbers of nematode infective juveniles emerging from insects that had been infected with $H$. downesi carrying either symbiont subspecies and then allowed to desiccate for up to 62 days. In moist conditions, cadavers produced similar numbers of nematodes, irrespective of the symbiont subspecies present, while under desiccating conditions, $P$. temperata subsp. cinerea cadavers yielded more nematode progeny than $P$. temperata subsp. temperata cadavers. Desiccating cadavers with the same nematode isolates, carrying either one or the other symbiont subspecies, confirmed that the symbiont was responsible for differences in nematode survival. Moreover, cadavers harbouring $P$. temperata subsp. cinerea had a reduced rate of drying relative to cadavers harbouring $P$. temperata subsp. temperata. Our experiments support the hypothesis that $H$. downesi can extend its niche into harsher conditions by associating with P. temperata subsp. cinerea.

Keywords Symbiosis $\cdot$ Host fitness $\cdot$ Microbes $\cdot$ Desiccation tolerance

\section{Introduction}

Bacterial symbionts are increasingly recognised as mediators of ecologically important traits of animals, with significant involvement in the host's adaptation to its niche [1-4]. Where horizontal transfer is possible, uptake of a new symbiont may result in the acquisition of new traits [5, 6]. In aphids, horizontal transfer of facultative symbionts is associated with 
aphid lineages colonising new ecological niches, including novel host plant species and climatic regions [6]. Entomopathogenic nematodes are recognised as important and tractable model systems for studies of symbiosis [7, 8], but the possibility of symbiont acquisition facilitating niche expansion has received little attention to date.

Entomopathogenic nematodes of the genera Heterorhabditis and Steinernema are mutualistically associated with insect pathogenic members of the Enterobacteriaceae, Photorhabdus and Xenorhabdus, respectively. The two associations share many features in common, presumably as a result of convergent evolution [9], though the details of the symbioses vary. The freeliving stage of the nematode, the infective juvenile (IJ), carries cells of its symbiont in its gut. In Steinernema, they are carried in a specialised intestinal receptacle [10] while in Heterorhabditis, they are found in the intestinal lumen [11]. When the IJ enters an insect, it releases the bacteria which proliferate, assist in killing the insect and convert it to a nutritive soup that supports development and reproduction of the nematodes. After 2-3 weeks the cadaver is depleted and tens or hundreds of thousands of IJs emerge to seek new hosts. In Heterorhabditis, transmission of the symbiont is vertical, occurring within the mother nematode, while in Steinernema, it is horizontal, occurring within the insect cadaver [7, 12]. Maternal transmission of the symbiont has been described for P. luminescens in H. bacteriophora [12]. Initially, the rectal gland of the mother nematode is colonised by the symbiont, and cells are later released into the mother's body cavity where they colonise the juveniles developing there. A single bacterium invades each of two pharyngeal gland cells in the intestine of the developing juvenile. The bacteria replicate and then emerge to colonise the IJ's intestine [12]. Since the Heterorhabditis mother is itself colonised from the insect cadaver, there is also scope for horizontal transfer in heterorhabditids.

There is a degree of specificity in the nematode-bacterial association, both in terms of nutritional support for nematode development and reproduction and retention of symbiont within the IJ intestine [13]. In nature, each species of Steinernema carries only one species of Xenorhabdus, though a given bacterial species may be associated with more than one species of nematode [14, 15]. For Heterorhabditis, the relationship is more variable; a single Heterorhabditis species may be naturally associated with more than one Photorhabdus subspecies or even species [13, 16-18]. For the most part, however, the different Photorhabdus variants are carried by different strains of the Heterorhabditis species and at different geographic locations; there is only one report of a Heterorhabditis associated with diverse Photorhabdus taxa within a site [19]. Laboratory studies demonstrate the potential for horizontal transfer of symbionts between species and strains of entomopathogenic nematodes, both Steinernema [20-22] and Heterorhabditis [23-26], and co-phylogenetic studies suggest that symbiont transfer events have occurred in the organisms' history [18, 22]. Together, these studies show that new combinations of nematode and symbiont are possible (within limits) and that symbionts differentially affect the fitness of the nematode. However, horizontal transfer of symbionts and symbiont-dependent traits has not previously been studied in an ecological context for any entomopathogenic nematode.

Two phenotypically distinct forms of Photorhabdus sp. associated with $H$. downesi were recorded in a dune system at North Bull Island in Dublin Bay and designated purple and yellow based on the colour of infected insect cadavers [27]. The two colour phenotypes were observed to differ in their spatial distributions within the dune system, with the purple phenotype dominating near the beach (within about $50 \mathrm{~m}$ of it). In a follow-up sampling, the dominance of the purple phenotype over the yellow within $0-40 \mathrm{~m}$ of the beach was confirmed (Rolston, Meade, Downes, unpublished). Coastal sand dunes represent a linear gradient from sparsely vegetated mobile sand at the front (near the beach) to full vegetation cover in the rear, with increasing gradients of soil humic matter and falling $\mathrm{pH}$. In the front of the dunes, soil moisture content is more variable since sandy soil loses moisture quickly due to its unstructured nature and low humic content $[28,29]$. In addition, accompanying the vegetational succession of coastal dune systems, there is also a succession in soil invertebrates (including potential hosts) with fewer, more specialised species in the foredunes and a more varied invertebrate fauna including typical grassland species further inland [30, 31].

We hypothesise that, by associating with the purple phenotype, H. downesi can extend its ecological niche, increasing its characteristic abundance in the harsher conditions of the front dunes. To test this, we ask whether the North Bull Island $H$. downesi can carry either symbiont subspecies, irrespective of which it carried when isolated from the field, and whether the symbionts differ significantly in traits adaptive for this habitat. Several studies have demonstrated that the insect cadaver can protect steinernematids and heterorhabditids within it from unfavourable environmental conditions including desiccation [32-35]. Since the cadaver is greatly modified by the bacterial symbiont, both by digestion and by the production of secondary metabolites [36, 37], we hypothesise that different symbionts may affect the protective qualities of the cadavers; specifically, that the purple phenotype will give greater within-cadaver protection to nematodes than will the yellow. We also look for evidence of host adaptation in the symbionts, either in virulence or ability to support reproduction of H. downesi. Thus, the objectives of this paper are to (1) confirm the distribution of the yellow and purple symbionts at North Bull Island and (2) to identify them, (3) assess the ability of $H$. downesi isolated with one symbiont phenotype to carry the other one, and (4) look for differences between the symbionts that might confer fitness benefits on their nematode 
host, specifically, in-cadaver desiccation tolerance, and ability to kill and multiply in different insect species under nondesiccating conditions.

\section{Methods}

\section{Study Location}

North Bull Island $\left(53^{\circ} 58^{\prime} \mathrm{N}, 6^{\circ} 15^{\prime} \mathrm{W}\right)$ is a growing, 200year-old, primarily sand island in Dublin Bay, Ireland, lying entirely within Ireland's capital city. This island, which is approximately $5 \mathrm{~km}$ long and $800 \mathrm{~m}$ wide, is a National Nature Reserve and a Special Area of Conservation under the EU Habitats Directive, but also heavily used for recreation [38].

\section{Distribution of $\boldsymbol{H}$. downesi in North Bull Island}

Soil samples were collected in September-October 2008 along three transects, $500 \mathrm{~m}$ apart (see Suppl. Fig 2). Each transect ran from the dune front at the beach into the fescuedominated closed grassland farther inland. A transect consisted of 14 sampling locations at 10-m intervals. The most seaward sampling location was in the first embryonic dune, approximately $2 \mathrm{~m}$ from the front of the dune vegetation. In 2012, sampling was repeated at the location of the 2008 transect 1 . At this stage, the dunes had extended farther seaward by about $20 \mathrm{~m}$, so 16 sampling locations were required to cover the 2008 transect plus the newly formed dunes. The habitat at each sampling location was classified according to Fossitt [39] as modified by Rodwell [28]. At each sampling location, there was a composite sample of about 30 soil cores (10 cm depth $\times 1.2 \mathrm{~cm}$ diam.) taken along a line (approx. $20 \mathrm{~m}$ ) perpendicular to the transect line. Samples were baited [40] with final-instar larvae of the greater wax moth (Galleria mellonella) (Mealworm Company, Sheffield, UK) at $20{ }^{\circ} \mathrm{C}$. Heterorhabditis-infected cadavers were recognised by luminescence and characteristic colour, either yellow (straw colour darkening to yellow) or purple (achromatic darkening to purple). Each cadaver was placed individually in a White trap [41] and incubated at $20^{\circ} \mathrm{C}$ to collect emerging IJs. IJs were surface sterilised in $0.16 \mathrm{mM}$ Hyamine 1622 solution (SigmaAldrich) for $15 \mathrm{~min}$, and about $1000 \mathrm{IJs}$ were used to infect G. mellonella larvae to establish cultures [42]. For analysis, data from the 2008 and 2012 sampling periods were combined, and the location (metres from the start of transect) of samples yielding yellow and purple phenotypes was compared using Mann Whitney $U$ test.

The organic matter content of soil samples was determined by loss on ignition and calculated using the percentage by weight method [43]. Water-holding capacity was determined for $100 \mathrm{~g}$ sieved fresh samples (5-mm sieve) [44].

\section{Nematodes and Bacteria}

Nematodes and bacteria originating from six bait cadavers, three of each phenotype, were identified. All six isolates were from transect 1 in 2008. The "purple" isolates, designated pur1, pur2 and pur3, were recovered from samples at 20, 30 and $60 \mathrm{~m}$, respectively, while the "yellow" isolates yel1, yel2 and yel3 were from 80, 90 and $120 \mathrm{~m}$, respectively. For each sample location, IJs originating from one randomly chosen bait insect cadaver were used as the basis of the isolate. Bacteria were isolated from the haemolymph of surfacesterilised G. mellonella larvae infected with the respective nematode isolates [41]. Nematodes were routinely cultured in wax moth larvae at $20^{\circ} \mathrm{C}$ using standard procedures [41], and IJs were stored in tap water at $9{ }^{\circ} \mathrm{C}$.

\section{Molecular Characterisation of Nematodes and Their Associated Symbionts}

Bacterial and nematode (from IJs) DNA was extracted using a DNeasy blood and tissue kit (Qiagen, Crawley, UK). Amplification of DNA extract was carried out using primers specific for the ITS region of the rDNA for nematodes [45] or for the $g y r B$ gene, for bacteria [46], as described by the authors. PCR product was cloned using a TOPO TA Cloning ${ }^{\circledR}$ Kit (Life Technologies). Plasmid DNA was purified using a QIAprep ${ }^{\circledR}$ Spin Miniprep Kit (Qiagen). The nematode plasmid DNA was sequenced by LGC Genomics (Berlin, Germany) using M13 forward and reverse primers. The bacterial plasmid DNA was sequenced by GATC Biotech (Konstanz, Germany) using M13 forward and reverse primers plus four $g y r B$ specific primers [47] to obtain overlapping sequences.

Homologous nucleotide sequences in GenBank were identified using the blastn algorithm in BLAST (http://blast.ncbi. nlm.nih.gov/Blast.cgi) [48]. For nematodes, a total of 29 sequences and for bacteria, a total of 33 sequences were used to carry out multiple sequence alignments in MEGA5 [49] using ClustalW [50, 51]. The resulting alignments were trimmed to leave 1012 positions for nematodes and 847 positions for bacteria. Phylogenetic analysis was carried out in MEGA5, with the choice of model determined using the "Find Best DNA/Protein Models (ML)" option. Evolutionary history based on the Kimura 2-parameter nucleotide substitution model was estimated using the maximum likelihood method [52] with a Gamma distribution used to model nonuniform rates between sites. A phylogenetic tree using bootstrap analysis with 1000 replicates was constructed using Caenorhabditis elegans or X. nematophila as outgroup for nematodes and bacteria, respectively. For bacteria, nucleotide sequences were translated and open reading frames in the protein sequence were identified using ORF Finder (http://www.ncbi.nlm.nih.gov/gorf/gorf.html). 


\section{Routine Distinction Between P. temperata Subspecies}

We used colour phenotype for routine distinction between $P$. temperata subsp. temperata and P. temperata subsp. cinerea in experiments. The Bull Island strains of $P$. temperata subsp. temperata produce yellow pigment on nutrient agar and in insects. $P$. temperata subsp. cinerea is distinguished by the production of a salmon-coloured/grey pigment in the colony and grey pigment in the agar around older colonies [53]. Wax moth larvae infected by $P$. temperata subsp. temperata are yellow (occasionally orange) from the time of death, while those infected by $P$. temperata subsp. cinerea are initially achromatic (unchanged in colour), but turn purplish grey after about 2 days at $20{ }^{\circ} \mathrm{C}$. Under our culture conditions, these colony and cadaver phenotypes are invariant: P. temperata subsp. temperata always yellow, never grey/purple, and $P$. temperata subsp. cinerea always grey/purple, never yellow. We have validated the method by identifying colonies on plates with a mixture of both subspecies based on colony morphology and confirming the identification by PCR. In routine use in our experiments, we first check colonies/cadavers for bioluminescence (showing presence of $P$. temperata); colour phenotype is then used in the binary decision between the two subspecies.

\section{Quantification of Bacteria Carried by Individual Infective Juveniles}

IJs were surface sterilised in Hyamine 1622 solution $(0.16 \mathrm{mM})$ for $15 \mathrm{~min}$ and rinsed three times in sterile phosphate-buffered saline (PBS). Individual IJs were crushed by grinding with a sterile micropestle for $1 \mathrm{~min}$ in a $1.5 \mathrm{-ml}$ microcentrifuge tube containing $100 \mu \mathrm{l}$ PBS. A 50- $\mu$ l aliquot of the product was plated onto Luria-Bertani (LB) agar supplemented with $0.1 \%$ sodium pyruvate (LB pyruvate agar) and incubated in the dark at $27{ }^{\circ} \mathrm{C}$ for $48 \mathrm{~h}$ and $\mathrm{CFU}$ were counted. For each of the six wild-type $H$. downesi isolates, assessments were carried out on two independent culture batches with 20 IJs per batch (a total of 40 IJs per isolate for each of 5 isolates, 30 for pur2). Numbers of CFU/IJ were analysed by general linear model using Minitab 17 [54], with bacterial subspecies as fixed factor and isolate and culture batch as random factors.

\section{Symbiont Swapping Between $H$. downesi Isolates}

The primary objective of this experiment was to test whether $H$. downesi carrying one symbiont subspecies could carry the other subspecies if encountered in an insect cadaver. Two independent experiments were carried out with $H$. downesi isolates pur1 and yel3, carrying $P$. temperata subsp. cinerea and $P$. temperata subsp. temperata, respectively. These two nematode isolates were chosen as representing the extremes on the transect from which they were isolated, and hence most likely to differ genetically. In outline, wax moth larvae were first injected with $P$. temperata and then $H$. downesi IJs were allowed to invade the cadavers. Bacterial symbiont carried by emerging IJs was identified by plating crushed IJs and by a bioassay method.

Wax moth larvae were injected with $2.5 \mu \mathrm{l}$ saline containing $1 \times 10^{5}$ cells of $P$. temperata and incubated at $20^{\circ} \mathrm{C}$. There were three bacterial treatments: $P$. temperata subsp. cinerea (from $H$. downesi pur1), P. temperata subsp. temperata (from H. downesi yel3) and a 1:1 mix of both symbionts. After 3 days, representative cadavers were crushed and plated to confirm the presence of both symbionts in the mixtures. P. temperata colonies (confirmed by bioluminescence) were assigned to subspecies based on colony colour, and the total number of $P$. temperata colony forming units (CFU) was counted.

Three days after injection with $P$. temperata, 20 cadavers of each treatment were each exposed to $100 \mathrm{IJs}$ of $H$. downesi and incubated at $20^{\circ} \mathrm{C}$. Four days later, 10 cadavers per treatment were dissected to assess the number of nematodes that had invaded. After another 10 days (14 days after exposure to nematodes), the remaining 10 cadavers per treatment were placed in individual White traps to collect emerging IJs.

Emerging IJs were harvested for up to 26 days, and the yield (IJs/cadaver) was assessed. The subspecies of bacterial symbiont carried by the emerging IJs was assessed using a one-on-one bioassay [55], in which one IJ was placed in contact with a single final instar $G$. mellonella larva $(N=48$ per assessed source cadaver). Infection of test insects by $P$. temperata was confirmed by bioluminescence, and the $P$. temperata subspecies present was identified based on cadaver colour. In each experiment, IJs from each of the 10 (9 in trial 2) cadavers injected with the symbiont mix were assayed, while for the single-symbiont subspecies treatments, only IJs from 4 randomly chosen cadavers were assessed. In addition, for the single-bacteria treatments, IJs from all 10 cadavers per treatment were pooled and 20 randomly chosen IJs were each individually crushed and plated to verify subspecies identity and number carried.

The three bacterial treatments were compared for each of three response variables (number of CFU/cadaver $(\log 10$ transformed), number of nematodes invading cadavers, and number of IJs emerging from cadavers) using general linear models; bacterial treatment was a fixed factor and experiment was a random factor in each analysis. An interaction term was included, but was not significant in any case. For cadavers injected with a single subspecies of symbiont prior to infection by nematodes, the number of CFU/IJ carried by IJs emerging from cadavers injected with their own or with the other subspecies of symbiont was compared using a two-sample $t$ test for each nematode isolate separately. For the cadavers injected with a mixture of the two symbiont subspecies, the number of 
emerging IJs carrying either $P$. temperata subsp. cinerea or P. temperata subsp. temperata was compared using a Mann Whitney $U$ test using Minitab 17 [54].

\section{Effect of Symbiont Subspecies on Insect Mortality and Nematode Reproduction in Different Insect Hosts}

In the absence of knowledge of the natural hosts used by H. downesi, either at North Bull Island or elsewhere, we looked for differences between isolates carrying the two symbionts in virulence for and ability to support nematode reproduction in four species representing the three insect orders most commonly used as hosts by entomopathogenic nematodes-Coleoptera, Lepidoptera and Diptera [56, 57]. Species tested were Tenebrio molitor (mealworms) and Hylobius abietis (large pine weevil) (Coleoptera), G. mellonella (wax moths) (Lepidoptera), and Coelopa sp. (kelp flies) (Diptera). Late-instar larvae of each species were tested using standard laboratory assays (details in Supplementary materials, Section 5).

\section{Effect of Symbiont Subspecies on Nematode Survival in Insect Cadavers Under Desiccation}

Experiment 1. Wax moth larvae were infected with each of the six native isolates of $H$. downesi, three carrying $P$. temperata subsp. cinerea (pur1, pur2 and pur3), and three carrying $P$. temperata subsp. temperata (yel1, yel2 and yel3). Wax moth larvae weighing 201-366 mg were exposed separately to $40 \mathrm{H}$. downesi IJs per insect. Three days later, insects exhibiting evidence of nematode infection (death and characteristic colour change) were placed in dry sand which had been washed and then heat sterilised at $120{ }^{\circ} \mathrm{C}$ over night. Polypropylene pots $\left(4 \mathrm{~cm} \times 4.4 \mathrm{~cm}, H \times D ; 60 \mathrm{~cm}^{3}\right)$ were half filled with sand and a single cadaver was placed in each. The pot was then filled to the top and covered with a tight-fitting lid. The pots were sealed in polythene bags and incubated at $20^{\circ} \mathrm{C}$. After $28,42,53$ or 61 days, 10 replicate cadavers per isolate were removed from the sand and placed on moistened filter paper for $24 \mathrm{~h}$ to rehydrate before being placed individually in modified White traps to collect emerging IJs. Thus, for each symbiont subspecies, yields of 30 cadavers were assessed at each time point. Emerging IJs were harvested for up to 21 days after emergence began, and the total number of IJs that emerged from each cadaver was assessed. An additional 5 cadavers per isolate (controls) were maintained on moist tissue paper until placed individually on White traps.

The total number of IJs ranged from 0 to 195,360 across the traps, with 117 of 270 samples having no IJs. Hence, a zero inflated Poisson regression model [58] was fitted to the total number of IJs that emerged. This is a mixture model in which one component models the probability of being in the zero inflated group and the second component models the Poisson distributed count responses. Expected count values can be estimated and tests of comparisons can be performed by combining the two components of the model. The linear predictor in the probability component included the two categorical explanatory variables symbiont subspecies (P. temperata subsp. cinerea and $P$. temperata subsp. temperata) and time $(0,28,42,53$ and 61 days) but the interaction between the two variables was not needed. The linear predictor for the Poisson component included the categorical explanatory variables bacterial subspecies, time and the interaction between symbiont subspecies and time. A random effect was also included in this linear predictor to allow for variation from strain to strain within each symbiont subspecies, where the same variance was assumed within each subspecies. A difference in the total number of emerging IJs between P. temperata subsp. cinerea and P. temperata subsp. temperata was estimated and tested for at each time point. Model fitting was carried out using the nlmixed procedure in the SAS software version 9.3 [59].

Experiment 2. Wax moth larvae were infected with four sets of IJs originating from the symbiont-swapping experiment. These were $H$. downesi purl nematodes carrying either their own symbiont ( $P$. temperata subsp. cinerea) or the symbiont from $H$. downesi yel3 nematodes ( $P$. temperata subsp. temperata), and $H$. downesi yel3 nematodes with each of the two symbionts. Cadavers $(N=18)$ were placed in desiccators maintained at $0 \%$ relative humidity $(\mathrm{RH})$ using activated silica gel for 28 days. They were rehydrated and numbers of IJs emerging from each cadaver were assessed, as above. The number of nematodes emerging per cadaver was compared between treatments using a Kruskal Wallis test.

\section{Effect of Symbiont Subspecies on Cadaver Drying Rate Under Desiccation}

The weight loss of insect cadavers under dry conditions was assumed to be largely due to loss of water, and hence to represent the rate of drying. Wax moths were infected with nematodes carrying $P$. t. cinerea (pur1) and P. t. temperata (yel3). After three days, dead insects (10 per symbiont subspecies) were weighed before being placed in desiccators at $0 \% \mathrm{RH}$. They were then weighed at 3-day intervals thereafter, for up to 30 days, and the percentage of weight lost by each insect was calculated.

A repeated measures linear mixed model was fitted to the logit of the weight loss percentage values, where the logit transformation was used to satisfy model 
assumptions. The explanatory variables were bacterial subspecies, time and the interaction between bacterial subspecies and time, where time was a categorical variable with ten levels $(3,6,9,12,15,18,21,24,27$ and 30 days) and symbiont subspecies was also categorical with two levels ( $P$. temperata subsp. cinerea and $P$. temperata subsp. temperata). An unstructured covariance matrix was selected to model the repeated measures as this gave a lower AICc (Akaike information criterion corrected for small samples) value than compound symmetry or autoregressive structures. Model fitting was carried out using the mixed procedure in the SAS software version 9.3 [59].

\section{Results}

\section{Distribution and Habitat Association}

H. downesi was recovered from 13 soil samples in 2008 and 7 in 2012. Overall, purple symbiont (identified as P. temperata subsp. cinerea, see below) was detected in 13 sampling locations and yellow (P. temperata subsp. temperata) in 7 . While there was some overlap, P. temperata subsp. cinerea tended to occur closer to the dune front than $P$. temperata subsp. temperata (Fig. 1). The spatial distribution of the two subspecies differed significantly (Mann Whitney $U$ test, $W=101.5$, $P=0.006)$. In 2008, $P$. temperata subsp. cinerea was detected in all three transects whereas $P$. temperata subsp. temperata was detected in transect 1 only. In this transect, the distributions of the two symbiont subspecies did not overlap: $P$. temperata subsp. cinerea was detected at 20,30, 40 and $60 \mathrm{~m}$ from the dune front, while $P$. temperata subsp. temperata was detected further into the dune system at 80 , 90 and $120 \mathrm{~m}$. When transect 1 was re-sampled in 2012, a

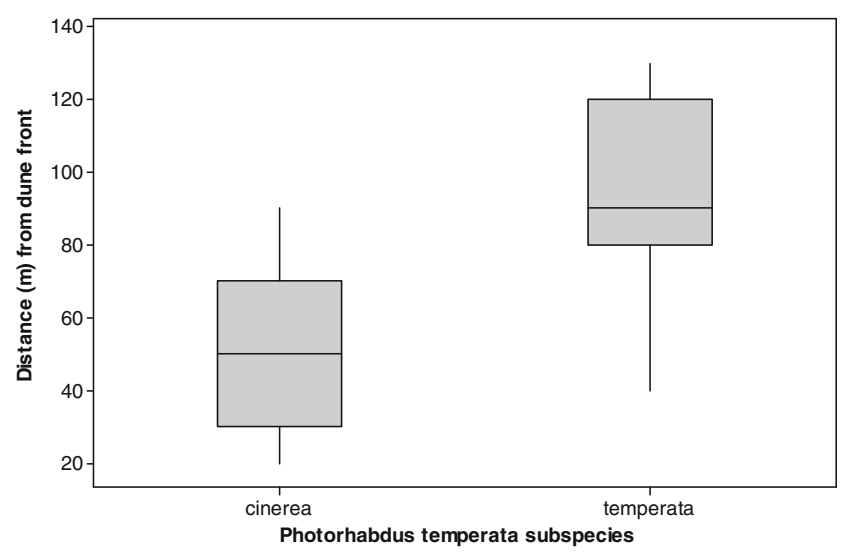

Fig. 1 Distance from the dune front of soil samples in which Heterorhabditis downesi carrying Photorhabdus temperata subsp. cinerea or Photorhabdus temperata subsp. temperata was detected in a sand dune system in North Bull Island, Dublin Bay. The box represents the inter-quartile range with the median shown as a line within it similar pattern emerged, though with some overlap: with P. temperata subsp. cinerea at 20,30 and $70 \mathrm{~m}$ and P. temperata subsp. temperata at 40,90,110 and $130 \mathrm{~m}$ (see Supplementary Figure 2).

While both bacterial subspecies were detected in nematodes from marram and semi-fixed/fixed dune habitats, $P$. temperata subsp. cinerea tended to occur where the ground cover was fragmented and marram grass was by far the dominant species; it was even recovered from recently formed embryonic dunes (Supplementary Table 1 and Supplementary Fig. 2). The front section of the dunes was cut across by many paths created by walkers, resulting in stretches of bare sand. Marram grass was present throughout the dune system but was not the dominant species beyond $60 \mathrm{~m}$ into the dune system. $P$. temperata subsp. temperata was more likely to be associated with fixed dune-type habitat. This habitat is characterised by broadleaved herbs [28, 39] and was the dominant habitat from $60 \mathrm{~m}$ into the dune system on transect 1 . Ground cover was more or less complete in the rear $60 \mathrm{~m}$ of the dunes, where a dense mat of living and dead plant material tended to accumulate, leaving few bare patches. Where this occurred, the soil was well shaded and tended to be more moist. Organic matter content rose from less than $1 \%$ at the start of the transect to 4 $5 \%$ in the rear $50 \mathrm{~m}$ of the transect. The water-holding capacity of samples ranged from $30(0.5 \% \mathrm{OM})$ to $56.3(5.6 \%$ OM) g water/100 g dry matter (Supplementary Fig. 3 and Supplementary Table 1).

\section{Identification of Nematodes and Associated Symbionts}

Analysis of the $\operatorname{gyr} B$ gene sequences showed that the purple and yellow bacterial isolates from North Bull Island belong to distinct subspecies of Photorhabdus temperata, P. temperata subsp. cinerea and $P$. temperata subsp. temperata, respectively (Fig. 2). The initial alignment of the edited nucleotide sequence of the six isolates showed single nucleotide polymorphisms (SNPs) at a total of 78 positions. At each SNP site all three isolates of each colour variant shared the same nucleotide and differed from the three isolates of the other colour variant.

All six nematode isolates were identified as $H$. downesi based on ITS1 sequence analysis. In the phylogenetic tree (Supplementary Fig. 4), the isolates clustered closely with two GenBank sequences for an Irish strain, $H$. downesi K122, produced by different laboratories. An initial alignment in ClustalW showed very little variation between the six isolates from North Bull Island with only seven SNPs occurring in the 1031 base portion of the ITS1 sequence analysed. There was no evidence of distinction between nematodes carrying the different symbionts as only a single isolate differed from the others at any of the seven positions where variation was detected. 


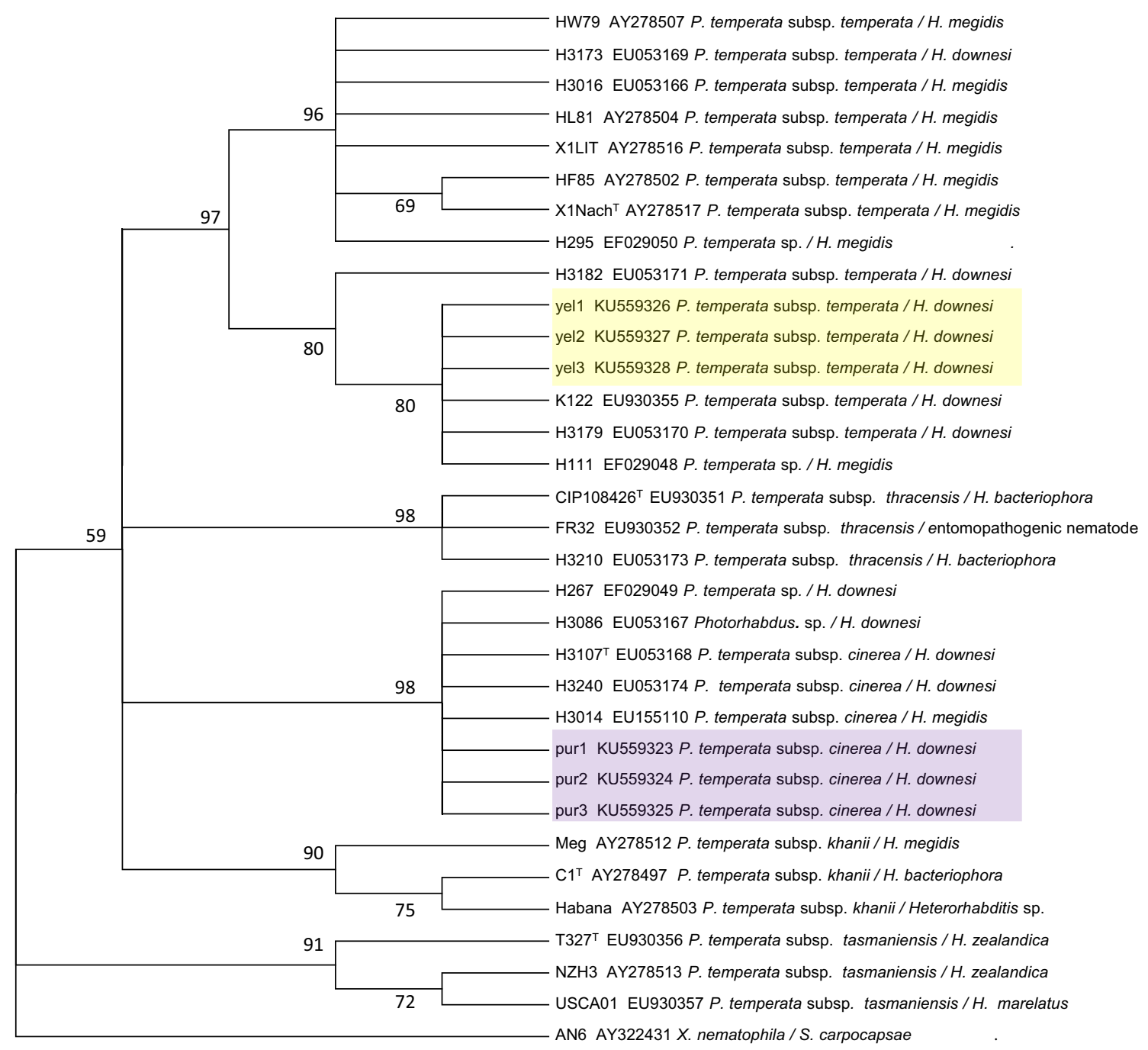

Fig. 2 Maximum Likelihood phylogenetic tree based on a portion (847 bp) of the gyrB gene from six North Bull Island isolates and members of the Photorhabdus temperata species. Xenorhabdus nematophila was used as an out-group. Tree shown is the bootstrap consensus tree from 1000 replications. Nematode hosts are also shown

\section{Number of Bacteria Carried by Individual Infective Juveniles}

There was no effect of symbiont subspecies $\left(F_{1,227}=0.11\right.$, $P=0.741)$ on the number of bacteria carried by IJs of the wild-type $H$. downesi isolates, with $297.5 \pm 13.09 \mathrm{CFU} / \mathrm{IJ}$ (mean $\pm \mathrm{SE})$.

\section{Symbiont Swapping Between Heterorhabditis downesi Isolates}

Based on colony colour phenotype, both symbiont subspecies were present in cadavers injected with a mixture of the symbionts. IJs of both $H$. downesi isolates, pur1 and yel3, invaded insects injected with either single or mixed $P$. temperata symbiont 3 days previously, and reproduced in and emerged from them as IJs. There were no differences amongst the three bacterial treatments (each of the two single symbiont subspecies alone, or a mixture of the two) for all three responses: number of $P$. temperata CFU/cadaver $\left(F_{2,25}=4.65\right.$, $P=0.155)$, number of nematodes invading the cadavers $\left(F_{2,54}=9.66, P=0.094\right)$ or in the number of nematode IJs emerging from them over subsequent weeks $\left(F_{2,53}=0.03\right.$, $P=0.869$ ) (data in Supplementary Table 3).

Based on the colour phenotype of colonies from crushed and plated individual IJs, all IJs emerging from cadavers injected with a single $P$. temperata subspecies treatment carried the subspecies with which the insect had been injected, irrespective of the P. temperata subspecies carried by the invading IJs, and both nematode isolates tested carried the same number of CFU of the non-native symbiont subspecies as of their native symbiont (two-sample $t$ test, $H$. downesi pur1: $T=1.25, P=0.225 \mathrm{DF}=24 ; H$. downesi yel3: $T=-0.84$, $P=0.410, \mathrm{DF}=24)$. Hybrid combinations derived from the 
symbiont-swapping experiment were subsequently stable over many cycles of laboratory culturing.

The one-on-one wax moth bioassay also showed that progeny IJs from each of the pure bacterial treatments always transmitted the bacteria with which the source insect had been injected, irrespective of the symbiont carried by the nematode invading the injected source cadaver (Supplementary Table 4). For the $P$. temperata subsp. cinerea/P. temperata subsp. temperata mix, IJs originating from 19 source cadavers were tested in the bioassay: in this test, IJs from 10 cadavers were found to all transmit $P$. temperata subsp. temperata, 4 produced only IJs transmitting P. temperata subsp. cinerea and 5 produced a mixture of IJs transmitting one or the other symbiont (Supplementary Table 5). There was a significant difference in the number of IJs associated with the two symbiont subspecies (Mann Whitney $U$ test, $W=284.0, P=0.01$ ), with more IJs carrying $P$. temperata subsp. temperata than $P$. temperata subsp. cinerea (median number of IJs/cadaver 13.0 and 0.0 , respectively; $N=19$ ). Overall, more than twice as many IJs emerging from cadavers injected with the symbiont mix carried $P$. temperata subsp. temperata as carried P. temperata subsp. cinerea (detected in 237 of the 333 successful one-on-one wax moth assays).

\section{Effect of Symbiont Subspecies on Insect Mortality and Nematode Reproduction in Different Insect Hosts}

Nematodes carrying both $P$. temperata subsp. cinerea and $P$. temperata subsp. temperata killed insects of all four test species and multiplied inside the three species in which reproduction was tested (Supplementary Table 6). There was no difference due to symbiont subspecies either in insect mortality or in the number of IJs emerging ( $P>0.05$ in each case).

\section{Effect of Symbiont Subspecies on Nematode Survival in Insect Cadavers Under Desiccation}

Experiment 1. There was evidence of a difference in the average numbers of IJs per cadaver between $P$. temperata subsp. cinerea and $P$. temperata subsp. temperata (three wild-type isolates of each) after 28, 42 and 53 days in dry sand $(P=0.031,<0.001$ and 0.009 respectively) but not after 0 (controls) days (Fig. 3). Thus, in cadavers that were maintained in moist conditions throughout (controls), symbiont subspecies did not affect the number of IJs emerging. All of these cadavers produced IJs, with an average of over a hundred thousand IJs per insect (mean $\pm \mathrm{SE}, 113,099 \pm 4816, N=30$ ). However, when cadavers were subjected to desiccation, generally fewer IJs emerged from those cadavers harbouring $P$. temperata subsp. temperata than from those with $P$. temperata subsp. cinerea, and after 2 months in dry sand, the only

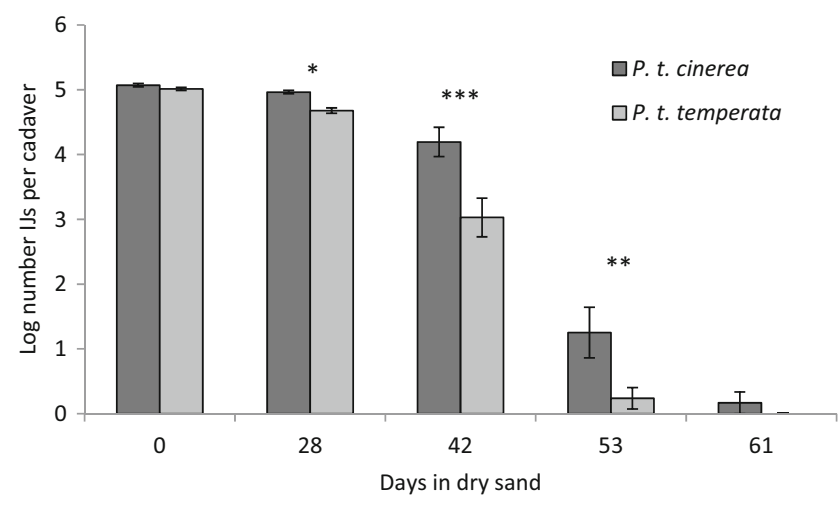

Fig. 3 Number of Heterorhabditis downesi infective juveniles (IJs) emerging from wax moth cadavers after various periods in dry sand ( $\log _{10}$ mean \pm SE IJs per cadaver). The nematodes used to infect the wax moths carried either Photorhabdus temperata subsp. cinerea or Photorhabdus temperata subsp. temperata. Asterisks indicate a significant difference between subspecies at a given time interval $(* P<0.05, * * P<0.01, * * * P<0.001)$

nematodes to emerge were from cadavers with P. temperata subsp. cinerea.

Experiment 2. There was a highly significant difference in numbers of IJs emerging between the four nematode/ bacterial combinations (Kruskal Wallis $H=16.50$, $\mathrm{DF}=3, P=0.001)$. For both $H$. downesi pur1 and yel3, more nematodes emerged from desiccated host cadavers when the invading nematodes carried $P$. temperata subsp. cinerea (median 7986.4 and 6355.9, respectively) than when the same nematode strain carried P. temperata subsp. temperata (median $=0$ in both cases; Fig. 4).

\section{Effect of Symbiont Subspecies on Cadaver Drying Rate Under Desiccation}

We found strong evidence of a difference in cadaver weight loss between symbiont subspecies after 12,15 and 18 days at $0 \% \mathrm{RH}(P<0.01$ in each test), weaker evidence of differences after 3, 6 and 9 days ( $P=0.028,0.042$ and 0.058 respectively), and no evidence of differences at the four later time points. Cadavers harbouring $P$. temperata subsp. cinerea lost weight more slowly than those harbouring $P$. temperata subsp. temperata, though both sets of insects eventually lost about $70 \%$ of their original weight during desiccation (Fig. 5).

\section{Discussion}

In this study, P. temperata subsp. cinerea tended to occur more towards the front of the dunes than $P$. temperata subsp. temperata. A similar pattern, with P. temperata subsp. cinerea predominating closer to the beach, was previously found at North Bull Island in 2001, 2002 [27] and 2005 (Rolston, Meade and Downes, unpublished). Thus, in each of 5 years 


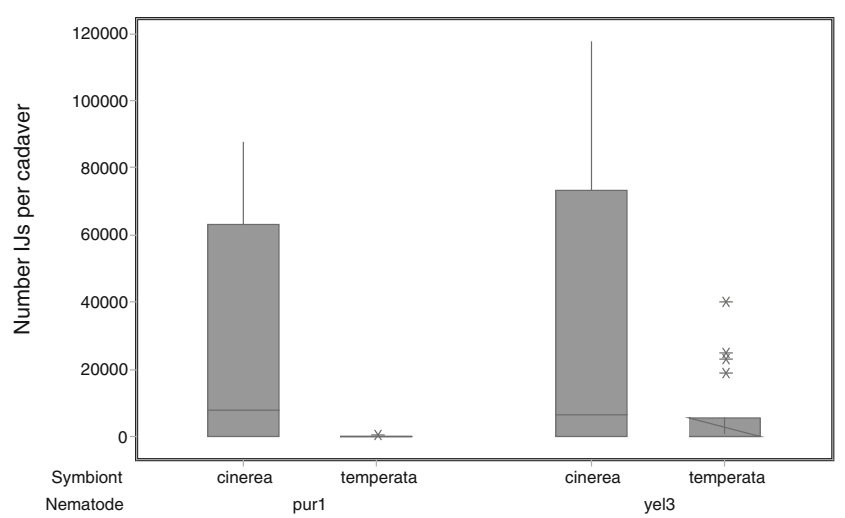

Fig. 4 Number of Heterorhabditis downesi infective juveniles (IJs) emerging from wax moth cadavers after 28 days at $0 \%$ relative humidity. The nematodes (pur1 and yel3) used to infect the wax moths each carried either Photorhabdus temperata subsp. cinerea or Photorhabdus temperata subsp. temperata. The box represents the inter-quartile range with the median shown as a line within it

from 2001 to 2012, H. downesi was associated with two P. temperata subspecies on North Bull Island, with P. temperata subsp. cinerea predominating in the front 40 $60 \mathrm{~m}$ of the dune system, pointing to the stability of the distribution. A number of gradients are typical of coastal sand dune systems, for example there is a progression from open sand to closed grassland as one moves from seaward to landward $[60,61]$. Associated with this gradient in vegetation cover, there is a change from loosely compacted sand which loses moisture quickly, to soil with a build-up of organic material within the soil profile and as litter overlaying the soil surface, both of which aid moisture retention [31]. Thus, the dune system is comprised of a number of different microhabitats, with different plant and animal communities both above and below ground, with the diversity of species increasing with distance into the dune system. There are several possible factors that could contribute to the observed distribution of symbiont types associated with $H$. downesi, with

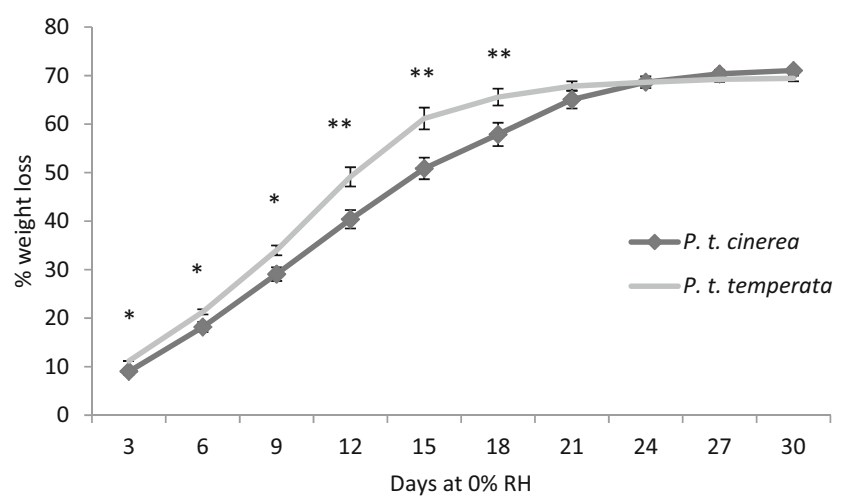

Fig. 5 Percentage weight loss of wax moth cadavers infected with Heterorhabditis downesi carrying either Photorhabdus temperata subsp. cinerea or Photorhabdus temperata subsp. temperata and incubated at $20{ }^{\circ} \mathrm{C}$ over silica gel at $0 \%$ relative humidity. Asterisks indicate a significant difference between subspecies at a given time interval $(* P<0.05, * * P<0.01)$ specialisation on different insect hosts being an obvious one. However, we found no difference between the two subspecies in ability to kill hosts from three insect orders or to support nematode development in them. There is a difference between the $H$. downesi symbionts in activity against bacteria and fungi; P. temperata subsp. cinerea demonstrated much stronger antimicrobial activity against members of both groups (unpublished data), but it is unclear as yet whether differences in antibiosis are important in adapting to local conditions in the dunes. The experiments reported here provide clear evidence of differential ability of the symbiont subspecies to protect nematodes within insect cadavers under dry conditions, correlating with the observed distribution of the subspecies. Under moist conditions, both symbiont subspecies gave a similar yield of IJs, whereas following desiccation, cadavers with $P$. temperata subsp. cinerea produced more IJs than those with $P$. temperata subsp. temperata, offering experimental evidence that the former really did provide better protection for the nematodes. And while the protective effect of the insect cadaver on entomopathogenic nematodes under desiccating conditions has previously been demonstrated for Heterorhabditis bacteriophora and for several species of Steinernema [32-34], the differential effect of symbiont subspecies has not been reported and raises significant ecological questions about niche extension and survival strategies of entomopathogenic nematode species.

Since emergence from desiccated cadavers usually began within a few days of being wetted, it is likely that IJ formation had already been completed and IJs emerged once they had recovered sufficiently, adequate moisture was available for movement and/or the insect cuticle had become sufficiently permissive for them to breach. IJs can persist for considerable lengths of time in cadavers under conditions that would be rapidly lethal to the same IJs in soil: slowing the rate at which water is lost is important in allowing nematode survival [62, 63]. Koppenhöfer et al. [33] suggested that the drying of the insect cuticle may act as a buffer against further moisture loss within the cadaver, and the host contents (partially digested tissues and bacterial biomass) may afford further protection. In our experiments, the rate at which cadavers lost weight differed between symbiont subspecies, with evidence that $P$. temperata subsp. cinerea slows the rate of drying relative to $P$. temperata subsp. temperata. Thus, the protective difference between subspecies may be at least partially explained by an effect on the drying rate of cadavers. Bacterial species and strains differ in their ability to survive drying, and amongst the mechanisms responsible for desiccation resistance is the production of extracellular polymeric substances, particularly exopolysaccharides [64-66]. Exopolysaccharides not only protect the bacterial cells but also modify the local environment, for example by altering soil water retention [67]. A novel polysaccharide has been identified in $P$. temperata subsp. cinerea (isolated from $H$. downesi in Hungary), which 
is unique amongst bacterial polysaccharide structures and differs significantly from those of $P$. temperata subsp. temperata and two other Photorhabdus species [68]. Since polysaccharides with different structure have different physical properties [69], production of disparate exopolysaccharides is a plausible mechanism by which bacterial strains might differentially affect the survival of organisms with which they associate.

Apart from differentially modifying the cadaver environment, it is possible that differences between the symbiont subspecies also affect the nematodes' stress tolerance directly. Under dry conditions, nematodes undergo various biochemical changes which allow them to survive desiccation, including the accumulation of polyols and sugars, alterations in fatty acid composition, and synthesis of several low molecular weight proteins $[63,70]$, any of which might be influenced by diet. In insects also, dietary factors can influence resistance to desiccation and other physical stresses [71-73]. For example, dietary live yeast promoted thermal tolerance in Drosophila, as well as altering total lipids and proteins and metabolic profiles [71]. Heterorhabditis species have nutritional requirements for specific Photorhabdus strains in order to reproduce [23-26], indicating that Photorhabdus taxa provide different nutritional factors, though the nature of these differences are largely unknown [8]. Additionally, potential protectant molecules may be taken up by nematodes across their cuticles $[74,75]$. All these suggest that $P$. temperata subsp. cinerea and $P$. temperata subsp. temperata are likely to convert the interior of their insect hosts to quite different media, upon which the multiplying nematodes feed or from which they may absorb different materials across their cuticles.

Whatever the reason for the differences between the $P$. temperata subspecies in the protection they confer on the nematodes within the cadaver, P. temperata subsp. cinerea clearly provides an advantage to its associated nematodes under dry conditions, such as may occur at the front of a dune system. While it is unlikely that such extreme drought would persist for weeks in Ireland, the effects of drying on organisms may be exacerbated by other adverse conditions in the dune sands, such as high temperatures and fluctuating salinity. Our experiments were conducted at $20{ }^{\circ} \mathrm{C}$ (within the optimum temperature range for this species), while the sand near the surface may reach $40{ }^{\circ} \mathrm{C}$ in summer [76], which would both increase the rate of drying and add additional thermal stress. Furthermore, the constant conditions of our experiments are not representative of those likely in the natural habitat, where bare sands are even more prone than normal soils to cycles of drought and re-wetting and extreme diurnal fluctuations of temperature [60]. Finally, the wax moth larvae used in our experiments are large relative to the typical hosts of entomopathogenic nematodes [77]; smaller hosts would be expected to lose moisture more rapidly.
Sequence analysis of the nematode ITS1 region showed no difference between $H$. downesi isolates carrying the different symbiont subspecies; there was as much variation within as between nematode isolates associated with the two subspecies. Over $99 \%$ identity was shared by all six isolates along the initial 1031 positions analysed, in contrast to the fournucleotide difference between $H$. bacteriophora isolates associated with different $P$. luminescens subspecies in the south of France [17]. AFLP analysis of $H$. downesi isolated from North Bull Island in 2005 showed genetic diversity within the population, but there was no evidence of the restricted gene flow that would be expected if the $H$. downesi isolates were unable to utilise each others' symbiont (A. Rolston, C. Meade \& M.J. Downes, unpublished data). Such relatively crude methods could easily fail to detect small strain differences, e.g. in genes for specificity factors such as surface structure recognition and gene regulation [7] [78]. However, based on the ease with which the symbiont subspecies were interchanged between nematode hosts in our experiments we would expect horizontal transfer of these symbionts to occur when $H$. downesi IJs carrying different symbionts co-infect an insect host in nature.

Both symbiont subspecies colonised the same individual insects, as evidenced both by plating cadaver contents 3 days post injection and by detecting both symbionts in IJs emerging from co-injected cadavers. Overall, a higher proportion of IJs emerging from cadavers with the mixed bacterial treatment carried $P$. temperata subsp. temperata rather than $P$. temperata subsp. cinerea. However, this was not true for each individual cadaver: while IJs from most cadavers carried P. temperata subsp. temperata only, IJs from a minority of cadavers carried $P$. temperata subsp. cinerea only, and some cadavers produced a mixture of both types of IJ. This suggests that there is not a strict dominance hierarchy between the symbionts and that which one dominates within a host may be influenced by minor variations in conditions. Success of one subspecies relative to the other may be due to competitive growth within the cadaver, or to colonisation of either the mother nematode or IJ as described for P. luminescens colonising $H$. bacteriophora [12]. H. downesi IJs did not have a strong preference for one subspecies over the other, with similar numbers of IJs invading host cadavers harbouring either or both symbiont subspecies.

Toth \& Lakatos [19] reported the co-occurrence of the same two symbionts as we found in North Bull Island, $P$. temperata subsp. cinerea and $P$. temperata subsp. temperata associated with $H$. downesi at two sites in central Hungary, an oak forest and a clearing $1 \mathrm{~km}$ away. Although several samples were taken at each site, no details were given that would allow any conclusions about habitat association of the symbionts. The co-occurrence of these two symbiont subspecies with $H$. downesi in locations as distant as Ireland and Hungary suggests that it may be a general phenomenon throughout the range of the species. We previously reported 
the occurrence of symbionts phenotypically resembling $P$. temperata subsp. cinerea and $P$. temperata subsp. temperata associated with $H$. downesi in Ireland and Britain [79]. Re-examination of records for that survey and another conducted on mainland Europe [80] indicates co-occurrence of the two symbiont subspecies with $H$. downesi at sites in Ireland (2/18 sites at which $H$. downesi was detected, not including North Bull Island), Wales (2/9) and Denmark (1/5) and occurrence of either one or the other symbiont at each of the other sites surveyed, all of which were sandy coastal sites. The results from North Bull Island show that the association of $H$. downesi with two symbiont subspecies in a single site has persisted there for at least a decade.

The true phylogenetic relationship between $H$. downesi's symbionts may be different than currently accepted: recent analysis based on multigene regions indicates that $P$. t. cinerea is more closely related to the newly described $P$. heterorhabditis than to $P$. temperata [81], indicating that the two $H$. downesi symbionts may in fact belong to different species of Photorhabdus. Whether species or sub-species, critical trait differences would be expected to facilitate niche separation and the co-existence of the two symbiont subspecies. Most importantly, those same differences would extend the niche of the nematodes. The low frequency and patchy distribution of Heterorhabditis populations [82] may make co-infection by strains carrying different symbionts infrequent, but as the invading Heterorhabditis IJs always develop into self-fertile hermaphrodites, two nematodes invading the same host can always reproduce (with cross-breeding in subsequent dioecious generations). As we have shown, nematodes emerging from a co-infected host can carry either symbiont subspecies. With those two factors in mind, we envisage a freely inter-breeding population of $H$. downesi, likely to exchange symbionts wherever IJs carrying different subspecies co-infect. The success of each symbiont subspecies in different microhabitats will depend, in part at least, on its ability to utilise and defend cadavers and to protect the progeny of its host nematode within them, the last of which is exemplified by the abilities of $P$. temperata subsp. cinerea in the front dunes.

Bacterial symbionts are mediators of ecologically important traits for their hosts. In the case of entomopathogenic nematodes, Photorhabdus and Xenorhabdus provide a range of services including nutrition, entomopathogenicity, suppression of the insect immune system and of competing microbes and scavenger deterrence [7,8]. With over 20 species of Xenorhabdus and at least 17 subspecies in total of the four species of Photorhabdus [81, 83], there is clearly scope for considerable diversity in the quality of each service, as demonstrated by Murfin et al. for Xenorhabdus bovienii in a coevolutionary framework [22]. Association with a new symbiont partner may confer novel traits on the host nematode, allowing colonisation of new or extended niches $[3,6]$.
Although Photorhabdus is maternally transmitted [7, 12], the possibility of host-switching in HeterorhabditisPhotorhabdus associations, identified as likely in a historical context by Maneesakorn et al. [18] in a co-phylogenetic study, has been demonstrated experimentally by Gerritsen et al. [84] and for the H. downesi-P. temperata associations that are the focus of our study. This study provides for the first time an ecological context of niche extension for an entomopathogenic nematode by changing its symbiotic partner.

In summary, we show that the entomopathogenic nematode $H$. downesi can readily swap the symbiont subspecies that it carries, by entering an insect host infected with another subspecies of $P$. temperata. The two symbiont subspecies differ in their ability to protect nematodes in insect hosts that are subject to desiccation. Nematodes occurring in the harsh foredunes of a coastal dune system, where low organic matter means that soil dries quickly, were more likely to be associated with the symbiont with which it could better survive desiccation (P. temperata subsp. cinerea) than the other one occurring at the same site (P. temperata subsp. temperata), suggesting that this ability to switch symbionts may facilitate niche expansion of H. downesi.

Acknowledgments A.M.D. Maher was funded by a doctoral fellowship from the Irish Research Council for Science, Engineering and Technology (IRCSET); M. Asaiyah was funded by a Postgraduate Scholarship from the Ministry of Higher Education and Scientific Research in Lybia. We are grateful to Dr. David Fitzpatrick for advice on bioinformatics and to Prof. M.J. Downes and the anonymous referees for their helpful comments on the manuscript.

\section{References}

1. Thrall PH, Hochberg ME, Burdon JJ, Bever JD (2007) Coevolution of symbiotic mutualists and parasites in a community context. Trends Ecol Evol 22:120-126

2. Douglas A (2009) The microbial dimension in insect nutritional ecology. Funct Ecol 23:38-47

3. Feldhaar H (2011) Bacterial symbionts as mediators of ecologically important traits of insect hosts. Ecol Entomol 36:533-543

4. Duperron S, Pottier M-A, Leger N, Gaudron SM, Puillandre N, Le Prieur SP, Sigwart JD, Ravaux J, Zbinden M (2013) A tale of two chitons: is habitat specialisation linked to distinct associated bacterial communities? FEMS Microbiol Ecol 83:552-567

5. Oliver KM, Degnan PH, Burke GR, Moran NA (2010) Facultative symbionts in aphids and the horizontal transfer of ecologically important traits. Annu Rev Entomol 55:247-266

6. Henry LM, Peccoud J, Simon J-C, Hadfield JD, Maiden MJ, Ferrari J, Godfray HCJ (2013) Horizontally transmitted symbionts and host colonization of ecological niches. Curr Biol 23:1713-1717

7. Chaston J, Goodrich-Blair H (2010) Common trends in mutualism revealed by model associations between invertebrates and bacteria. FEMS Microbiol Rev 34:41-58

8. Clarke DJ (2008) Photorhabdus: a model for the analysis of pathogenicity and mutualism. Cell Microbiol 10:2159-2167

9. Poinar GO (1993) Origins and phylogenetic relationships of the entomophilic rhabditids, Heterorhabditis and Steinernema. Fundam Appl Nematol 16:333-338 
10. Martens EC, Heungens K, Goodrich-Blair H (2003) Early colonization events in the mutualistic association between Steinernema carpocapsae nematodes and Xenorhabdus nematophila bacteria. J Bacteriol 185:3147-3154

11. Ciche T, Ensign J (2003) For the insect pathogen Photorhabdus luminescens, which end of a nematode is out? Appl Environ Microbiol 69:1890-1897

12. Ciche TA, Kim KS, Kaufmann-Daszczuk B, Nguyen KCQ, Hall DH (2008) Cell invasion and matricide during Photorhabdus luminescens transmission by Heterorhabditis bacteriophora nematodes. Appl Environ Microbiol 74:2275-2287

13. Adams BJ, Fodor A, Koppenhofer HS, Stackebrandt E, Stock SP, Klein MG (2006) Biodiversity and systematics of nematodebacterium entomopathogens. Biol Control 37:32-49

14. Akhurst R, Boemare N, Gaugler R, Kaya H (1990) Biology and taxonomy of Xenorhabdus. In: Gaugler R, Kaya HK (eds) Entomopathogenic nematodes in biological control. CRC Press, Boca Raton, pp 75-90

15. Lee MM, Stock SP (2010) A multilocus approach to assessing coevolutionary relationships between Steinernema spp. (Nematoda: Steinernematidae) and their bacterial symbionts Xenorhabdus spp. ( $\gamma$ - Proteobacteria: Enterobacteriaceae). Syst Parasitol 77:1-12

16. Noujeim E, Khater C, Pages S, Ogier J-C, Tailliez P, Hamze M, Thaler O (2011) The first record of entomopathogenic nematodes (Rhabiditiae: Steinernematidae and Heterorhabditidae) in natural ecosystems in Lebanon: a biogeographic approach in the Mediterranean region. J Invertebr Pathol 107:82-85

17. Emelianoff V, Le Brun N, Pagès S, Stock SP, Tailliez P, Moulia C, Sicard M (2008) Isolation and identification of entomopathogenic nematodes and their symbiotic bacteria from Hérault and Gard (Southern France). J Invertebr Pathol 98:211-217

18. Maneesakorn P, An RS, Daneshvar H, Taylor K, Bai XD, Adams BJ, Grewal PS, Chandrapatya A (2011) Phylogenetic and cophylogenetic relationships of entomopathogenic nematodes (Heterorhabditis: Rhabditida) and their symbiotic bacteria (Photorhabdus: Enterobacteriaceae). Mol Phylogenet Evol 59: 271-280

19. Tóth T, Lakatos T (2009) Two different bacterial symbionts of Heterorhabditis megidis and Heterorhabditis downesi inside one population. IOBC/WPRS Bull 45:395-397

20. Sicard M, Ferdy JB, Pages S, Le Brun N, Godelle B, Boemare N, Moulia C (2004) When mutualists are pathogens: an experimental study of the symbioses between Steinernema (entomopathogenic nematodes) and Xenorhabdus (bacteria). J Evol Biol 17:985-993

21. Sicard M, Ramone H, Le Brun N, Pagès S, Moulia C (2005) Specialization of the entomopathogenic nematode Steinernema scapterisci with its mutualistic Xenorhabdus symbiont. Naturwissenschaften 92:472-476

22. Murfin KE, Lee M-M, Klassen JL, McDonald BR, Larget B, Forst S, Stock SP, Currie CR, Goodrich-Blair H (2015) Xenorhabdus bovienii strain diversity impacts coevolution and symbiotic maintenance with Steinernema spp. nematode hosts. mBio 6:e00076-15

23. Gerritsen LJM, Smits PH (1993) Variation in pathogenicity of recombinations of Heterorhabditis and Xenorhabdus luminescens strains. Fundam Appl Nematol 16:367-373

24. Gerritsen LJM, Smits PH (1997) The influence of Photorhabdus luminescens strains and form variants on the reproduction and bacterial retention of Heterorhabditis megidis. Fundam Appl Nematol 20:317-322

25. Han R, Wouts W, Li L (1991) Development and virulence of Heterorhabditis spp. strains associated with different Xenorhabdus luminescens isolates. J Invertebr Pathol 58:27-32

26. Han RC, Ehlers RU (1998) Cultivation of axenic Heterorhabditis spp. dauer juveniles and their response to non-specific Photorhabdus luminescens food signals. Nematologica 44:425-435
27. Rolston AN, Griffin CT, Downes MJ (2005) Distribution of entomopathogenic nematodes in an Irish sand dune system. Nematology 7:259-266

28. Rodwell JS, Birks HJB, Malloch AJC (2000) Shingle, strandline and sand-dune communities. In: Rodwell JS (ed) British plant communities, vol 5. Cambridge University Press, Cambridge, pp 113-250

29. Verhoeven R (2002) The structure of the microtrophic system in a development series of dune soils. Pedobiologia 46:75-89

30. Speight MC (1997) Invertebrates of dune and grassland. In: Jeffrey DW (ed) North Bull Island Dublin Bay - a modern coastal natural history. The Royal Dublin Society, Dublin, pp 107-111

31. McLachlan A, Brown AC (2006) The ecology of sandy shores. Elsevier, London

32. Serwe-Rodriguez J, Sonnenberg K, Appleman B, Bornstein-Forst S (2004) Effects of host desiccation on development, survival, and infectivity of entomopathogenic nematode Steinernema carpocapsae. J Invertebr Pathol 85:175-181

33. Koppenhöfer AM, Baur ME, Stock SP, Choo HY, Chinnasri B, Kaya HK (1997) Survival of entomopathogenic nematodes within host cadavers in dry soil. Appl Soil Ecol 6:231-240

34. Spence KO, Stevens GN, Arimoto H, Ruiz-Vega J, Kaya HK, Lewis EE (2011) Effect of insect cadaver desiccation and soil water potential during rehydration on entomopathogenic nematode (Rhabditida: Steinernematidae and Heterorhabditidae) production and virulence. J Invertebr Pathol 106:268-273

35. Lewis EE, Shapiro-Ilan DI (2002) Host cadavers protect entomopathogenic nematodes during freezing. J Invertebr Pathol 81:25-32

36. Webster JM, Chen G, Hu K, Li J (2002) Bacterial metabolites. In: Gaugler R (ed) Entomopathogenic nematology. CABI Publishing, Wallingford, pp 99-113

37. Bode HB (2009) Entomopathogenic bacteria as a source of secondary metabolites. Curr Opin Chem Biol 13:224-230

38. McCorry M, Ryle T (2009) A management plan for North Bull Island. Dublin City Council, Dublin

39. Fossitt JA (2000) A guide to habitats in Ireland. Heritage Council, Kilkenny

40. Bedding R, Akhurst R (1975) A simple technique for the detection of insect parasitic rhabditid nematodes in soil. Nematologica 21: $109-110$

41. Kaya HK, Stock PS (1997) Techniques in insect nematology. In: Lacey LA (ed) Manual of techniques in insect pathology. Academic, London, pp 281-324

42. Woodring JL, Kaya H (1988) Steinernematid and heterorhabitid nematodes: a handbook of biology and techniques. Arkansas Agricultural Experiment Station, Fayetteville

43. Hoogsteen MJJ, Lantinga EA, Bakker EJ, Groot JCJ, Tittonell PA (2015) Estimating soil organic carbon through loss on ignition: effects of ignition conditions and structural water loss. Eur J Soil Sci 66:320-328

44. Harding DE, Ross DJ (1964) Some factors in low-temperature storage influencing mineralisable-nitrogen of soils. J Sci Food Agric $15: 829-834$

45. Vrain TC, Wakarchuk DA, Levesque AC, Hamilton RI (1992) Intraspecific rDNA restriction-fragment-length-polymorphism in the Xiphinema-americanum group. Fundam Appl Nematol 15: 563-573

46. Tailliez P, Boemare N (2009) Phylogenetic studies with entomopathogenic bacteria with special emphasis on symbionts of entomopathogenic nematodes. In: Stock SP, Vanderberg J, Glazer I, Boemare N (eds) Insect pathogens: molecular approaches and techniques. CAB International, Wallingford, pp 131-144

47. Boemare N, Tailliez P (2009) Molecular approaches and techniques for the study of entomopathogenic bacteria. In: Stock SP, Vanderberg J, Glazer I, Boemare N (eds) Insect pathogens: molecular approaches and techniques. CAB International, Wallingford, pp 32-49 
48. Altschul SF, Madden TL, SchÃaffer AA, Zhang J, Zhang Z, Miller W, Lipman DJ (1997) Gapped BLAST and PSI-BLAST: a new generation of protein database search programs. Nucleic Acids Res 25:3389-3402

49. Tamura K, Peterson D, Peterson N, Stecher G, Nei M, Kumar S (2011) MEGA5: molecular evolutionary genetics analysis using maximum likelihood, evolutionary distance, and maximum parsimony methods. Mol Biol Evol 28:2731-2739

50. Larkin MA, Blackshields G, Brown N, Chenna R, McGettigan PA, McWilliam H, Valentin F, Wallace IM, Wilm A, Lopez R (2007) Clustal W and Clustal X version 2.0. Bioinformatics 23:2947-2948

51. Thompson JD, Higgins DG, Gibson TJ (1994) CLUSTAL W: improving the sensitivity of progressive multiple sequence alignment through sequence weighting, position-specific gap penalties and weight matrix choice. Nucleic Acids Res 22:4673-4680

52. Kimura M (1980) A simple method for estimating evolutionary rates of base substitutions through comparative studies of nucleotide sequences. J Mol Evol 16:111-120

53. Tóth T, Lakatos T (2008) Photorhabdus temperata subsp. cinerea subsp. nov., isolated from Heterorhabditis nematodes. Int J Syst Evol Microbiol 58:2579-2581

54. Minitab, Inc. (2015) Minitab 17 Statistical Software. State College, PA

55. Grewal PS, Converse V, Georgis R (1999) Influence of production and bioassay methods on infectivity of two ambush foragers (Nematoda : Steinernematidae). J Invertebr Pathol 73:40-44

56. Peters A (1996) The natural host range of Steinernema and Heterorhabditis spp. and their impact on insect populations. Biocontrol Sci Tech 6:389-402

57. Hominick WM (2002) Biogeography. In: Gaugler R (ed) Entomopathogenic nematology, vol 1. CAB International, Wallingford, pp 115-143

58. Ridout MS, Hinde JP, Demetrio CGB (1998) Models for count data with many zeros. Proceedings of the 19th International Biometric Conference. Cape Town, South Africa. pp 179-192

59. SAS Institute (2010) SAS Version 9.3. SAS Institute Inc., Cary, NC

60. Willis A, Folkes B, Hope-Simpson J, Yemm E (1959) Braunton Burrows: the dune system and its vegetation. J Ecol 47:249-288

61. Jeffrey DW (1977) Comparision of the habitats. In: Jeffrey DW (ed) North bull island Dublin Bay - a modern coastal natural history. RDS, Dublin, pp 26-31

62. Perry RN (1999) Desiccation survival of parasitic nematodes. Parasitology 119:S19-S30

63. Glazer I (2002) Survival biology. In: Gaugler R (ed) Entomopathogenic nematology. CABI, Wallingford, pp 169-187

64. Ferreira AS, Leitao JH, Silva IN, Pinheiro PF, Sousa SA, Ramos CG, Moreira LM (2010) Distribution of cepacian biosynthesis genes among environmental and clinical Burkholderia strains and role of cepacian exopolysaccharide in resistance to stress conditions. Appl Environ Microbiol 76:441-450

65. Greene C, Vadlamudi G, Newton D, Foxman B, Xi CW (2016) The influence of biofilm formation and multidrug resistance on environmental survival of clinical and environmental isolates of Acinetobacter baumannii. Am J Infect Control 44:E65-E71

66. Espinal P, Marti S, Vila J (2012) Effect of biofilm formation on the survival of Acinetobacter baumannii on dry surfaces. J Hosp Infect 80:56-60

67. Rossi F, Potrafka RM, Pichel FG, De Philippis R (2012) The role of the exopolysaccharides in enhancing hydraulic conductivity of biological soil crusts. Soil Biol Biochem 46:33-40

68. Kondakova AN, Kirsheva NA, Arbatsky NP, Shaikhutdinova RZ, Shashkov AS, Ivanov SA, Anisimov AP, Knirel YA (2015) Structure of a zwitterionic O-polysaccharide from Photorhabdus temperata subsp. cinerea 3240. Carbohydr Res 407:1-4

69. Rinaudo M (2004) Role of substituents on the properties of some polysaccharides. Biomacromolecules 5:1155-1165
70. Grewal PS, Bornstein-Forst S, Burnell AM, Glazer I, Jagdale GB (2006) Physiological, genetic, and molecular mechanisms of chemoreception, thermobiosis, and anhydrobiosis in entomopathogenic nematodes. Biol Control 38:54-65

71. Colinet H, Renault D (2014) Dietary live yeast alters metabolic profiles, protein biosynthesis and thermal stress tolerance of Drosophila melanogaster. Comp Biochem Physiol A Mol Integr Physiol 170:6-14

72. Sisodia S, Singh BN (2012) Experimental evidence for nutrition regulated stress resistance in Drosophila ananassae. PLoS One 7, e46131

73. Andersen LH, Kristensen TN, Loeschcke V, Toft S, Mayntz D (2010) Protein and carbohydrate composition of larval food affects tolerance to thermal stress and desiccation in adult Drosophila melanogaster. J Insect Physiol 56:336-340

74. Qiu L, Bedding RA (2002) Characteristics of protectant synthesis of infective juveniles of Steinernema carpocapsae and importance of glycerol as a protectant for survival of the nematodes during osmotic dehydration. Comp Biochem Physiol B: Biochem Mol Biol 131:757-765

75. Qiu L, Lacey MJ, Bedding RA (2000) Permeability of the infective juveniles of Steinernema carpocapsae to glycerol during osmotic dehydration and its effect on biochemical adaptation and energy metabolism. Comp Biochem Physiol B: Biochem Mol Biol 125: 411-419

76. Huiskes AHL (1979) Ammophila arenaria (L.) Link (Psamma arenaria (L.) Roem. et Schult.; Calamgrostis arenaria (L.) Roth). J Ecol 67:363-382

77. Půža V, Mráček Z (2005) Seasonal dynamics of entomopathogenic nematodes of the genera Steinernema and Heterorhabditis as a response to abiotic factors and abundance of insect hosts. J Invertebr Pathol 89:116-122

78. Lewis EE, Clarke DJ (2012) Nematode parasites and entomopathogens. In: Vega FE, Kaya HK (eds) Insect pathology, 2nd edn. Academic, San Diego, pp 395-424

79. Griffin CT, Joyce SA, Dix I, Burnell AM, Downes MJ (1994) Characterisation of the entomopathogenic nematode Heterorhabditis (Nematoda: Heterorhabditidae) from Ireland and Britain by molecular and cross-breeding techniques, and the occurrence of the genus in these islands. Fundam Appl Nematol 17:245253

80. Griffin CT, Dix I, Joyce SA, Burnell AM, Downes MJ (1999) Isolation and characterisation of Heterorhabditis spp. (Nematoda : Heterorhabditidae) from Hungary, Estonia and Denmark. Nematology 1:321-332

81. Ferreira T, van Reenen CA, Endo A, Tailliez P, Pages S, Sproer C, Malan AP, Dicks LMT (2014) Photorhabdus heterorhabditis sp. nov., a symbiont of the entomopathogenic nematode Heterorhabditis zealandica. Int J Syst Evol Microbiol 64:1540-1545

82. Stuart RJ, Barbercheck ME, Grewal PS, Taylor RAJ, Hoy CW (2006) Population biology of entomopathogenic nematodes: concepts, issues, and models. Biol Control 38:80-102

83. Tailliez P, Laroui C, Ginibre N, Paule A, Pages S, Boemare N (2010) Phylogeny of Photorhabdus and Xenorhabdus based on universally conserved protein-coding sequences and implications for the taxonomy of these two genera. Proposal of new taxa: $X$. vietnamensis sp nov., $P$. luminescens subsp caribbeanensis subsp nov., $P$. luminescens subsp hainanensis subsp nov., $P$. temperata subsp khanii subsp nov., $P$. temperata subsp tasmaniensis subsp nov., and the reclassification of $P$. luminescens subsp thracensis as $P$. temperata subsp thracensis comb. nov. Int J Syst Evol Microbiol 60:1921-1937

84. Gerritsen LJM, Wiegers GL, Smits PH (1998) Pathogenicity of new combinations of Heterorhabditis spp. and Photorhabdus luminescens against Galleria mellonella and Tipula oleracea. Biol Control 13:9-15 